\title{
Simulating Capacitive Micromachined Ultrasonic Transducers (CMUTs) using Field II
}

Bæk, David; Oralkan, Omer; Kupnik, Mario; Willatzen, Morten; Khuri-Yakub, Butrus T.; Jensen, Jørgen Arendt

\section{Published in:}

Proceedings of the 2010 IEEE International Ultrasonics Symposium

Link to article, DOI:

10.1109/ULTSYM.2010.5935580

Publication date:

2010

Document Version

Early version, also known as pre-print

Link back to DTU Orbit

Citation (APA):

Bæk, D., Oralkan, O., Kupnik, M., Willatzen, M., Khuri-Yakub, B. T., \& Jensen, J. A. (2010). Simulating Capacitive Micromachined Ultrasonic Transducers (CMUTs) using Field II. In Proceedings of the 2010 IEEE International Ultrasonics Symposium (pp. 439-442). IEEE. https://doi.org/10.1109/ULTSYM.2010.5935580

\section{General rights}

Copyright and moral rights for the publications made accessible in the public portal are retained by the authors and/or other copyright owners and it is a condition of accessing publications that users recognise and abide by the legal requirements associated with these rights.

- Users may download and print one copy of any publication from the public portal for the purpose of private study or research.

- You may not further distribute the material or use it for any profit-making activity or commercial gain

- You may freely distribute the URL identifying the publication in the public portal 


\title{
Simulating Capacitive Micromachined Ultrasonic Transducers (CMUTs) using Field II
}

\author{
David Bæk*, Ömer Oralkan ${ }^{\dagger}$, Mario Kupnik ${ }^{\dagger}$, Morten Willatzen ${ }^{\ddagger}$, Butrus T. Khuri-Yakub ${ }^{\dagger}$, and Jørgen Arendt Jensen* \\ ${ }^{*}$ Center for Fast Ultrasound Imaging, Department of Electrical Engineering, Technical University of Denmark \\ ${ }^{\dagger}$ Edward L. Ginzton Laboratory, Stanford University, Stanford, CA, USA \\ ${ }^{\ddagger}$ Mads Clausen Institute for Product Innovation, University of Southern Denmark, 6400 Sønderborg, Denmark \\ Email:db@elektro.dtu.dk,ooralkan@stanford.edu,kupnik@stanford.edu, \\ willatzen@mci.sdu.dk,khuri-yakub@stanford.edu, jaj@elektro.dtu.dk
}

\begin{abstract}
Field II has been a recognized simulation tool for piezoceramic medical transducer arrays for more than a decade. The program has its strength in doing fast computations of the spatial impulse response (SIR) from array elements by dividing the elements into smaller mathematical elements (ME)s from which it calculates the SIR responses. The program features predefined models for classical transducer geometries, but currently none for the fast advancing CMUTs. This work addresses the assumptions required for modeling CMUTs with Field II. It is shown that rectangular array elements, populated with cells, can be well approximated by neglecting the cells. Further, it is demonstrated that scaling of the SIR translates into better computational efficiency.
\end{abstract}

\section{INTRODUCTION}

The currently released version of the ultrasound simulation program Field II [1], [2] has been developed mainly with the classical piezoelectric medical ultrasound transducers in mind. Thus, all of the predefined transducer geometries in Field II are based on flat, curved, or double-curved transducers with rectangular elements. So far, piezoceramic transducers have been dominating the field of ultrasound imaging. However, for new transducer technologies, such as capacitive micromachined ultrasonic transducers (CMUTs) [5], the support in Field II has been limited.

In general, it is possible to model the emitted and received field from acoustic transducers with arbitrary geometry by applying the SIR method [3], [4] by using Field II. In case the geometry differs from the predefined ones, manual programming in Field II is required.

CMUT technology has become an enabling transducer technology, which has caught significant attention not only within the medical imaging community. CMUTs consist of multiple capacitive cells with one movable top electrode (plate), all electrically connected in parallel, to form transducer elements. These elements can be used in an arbitrary array configuration. The shape of the cells (e.g. circular, square, hexagon) and elements is defined by lithographical methods, which, besides high precision, provide good design flexibility and a wide possible operation frequency range.

Each top plate of the CMUT cells deflects due to an applied dc bias voltage and the ambient pressure. Modeling of each deflected cell with Field II requires a dense grid of MEs. MEs are Field II's subdivision of the transducer surface into smaller transducer elements of which a well known analytical solution to the SIR exists.

This paper addresses the assumptions needed for modeling the SIR of CMUT cells with Field II. It investigates the possibility of using a scaling of the SIR with the ratio of active and inactive area of a transducer element consisting of multiple cells.

\section{THEORY}

The field response from any flat piston transducer with a homogenous moving surface can be calculated with Field II using the SIR method. The pressure is calculated by convolving the surface acceleration with the SIR in emission. The pulse-echo SIR (PESIR) can be calculated by convolving the SIR in emission with the SIR in receive [9]. Modeling the SIR of curved surfaces, for which the analytical SIR is unknown, requires a subdivision of the surface into a dense grid of MEs. The total response is then calculated by superposition. This method is only valid under the assumption that each ME moves in the normal direction of the surface element that it represents, and it is a necessity that the wave propagation is linear. The SIR is a solution to the Rayleigh integral which limits its validity for highly curved transducers. Therefore, the integral does not account for the fact that a slightly curved transducer will introduce reflections and diffraction. However, these effects are negligible for the case of a small curvature compared to the wavelength and transducer size [10], [11], [12]. These are the underlying assumptions made for this work. a)

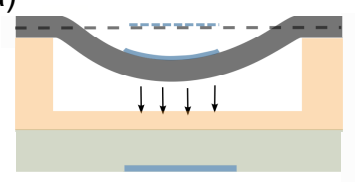

b)

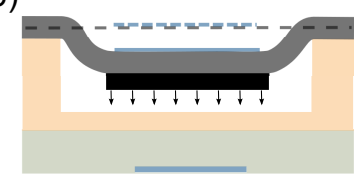

Fig. 1. Cross sections of regular CMUT (a) and Piston CMUT (b).

Analytical solutions to the SIR of curved transducers are very limited in literature. To the authors best knowledge, only for the special case of a circular cell shape with a spherical 


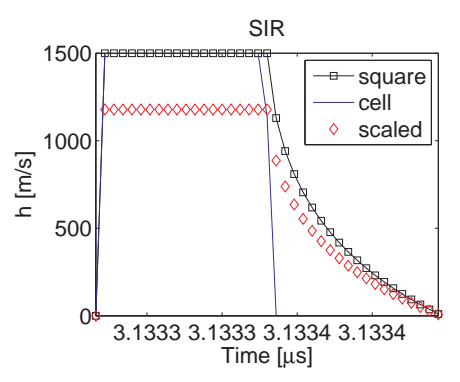

Fig. 2. SIRs for a square element, square, a flat circular cell, cell, and a scaled version of square, scaled. SF $10^{4} \mathrm{GHz}$. Only each $12 \mathrm{th}$ point is shown.

plate deflection can a simple analytical solution for the SIR be found see Arditi et al.[12].

Figure 1 shows the plate deflection for two types of CMUTs. One for regular CMUT cells and one for a CMUT that features a center mass in each plate, i.e., a piston CMUT, see [6]. Note that the plate material at the center of the regular CMUT cell is moving a larger vertical distance compared to the plate material closer to the post region. In addition, only the plate material right at the center of the cell features an entire perpendicular movement. Thus, we assume that during excitation, the ME representing the plate material closer to the post region, moves perpendicular to the surface segment that it represents. In the very near-field of the cell this assumption will not hold, thus, piston CMUT cells are more suitable for the SIR modeling approach. This is because a large fraction of the plate is moving as a real piston, and the rest of the plate will have a relatively small contribution to both the acoustic pressure field and the electrical field inside the vacuum sealed cavity. Hence, the validity of the Rayleigh integral is not so much compromised as for the regular CMUT cell. In general, the validity of the aforementioned assumptions becomes even more critical for other specific conditions or modes of operation. For example, CMUT plates that exceed a static deflection-to-thickness ratio of $20 \%$, i.e. when also in-plane stress starts to matter in terms of static and dynamic response of the plate [7]. Another example are CMUT cells that are biased beyond the pull-in point, i.e., when the plate experiences contact with the bottom of the cavity (collapse mode of operation) [8].

However, for cells that are arranged in a pattern to form a large aperture size transducer, the above-mentioned assumptions and approximations become less of a source of error, in particular at larger distances from the transducer surface. Hence, for medical imaging applications one can expect that the influence of the non-ideal radiation pattern from each individual cell will be very small. Further, note that acoustic cross-talk cannot be modeled for either CMUTs or piezoceramic transducers with Field II. Setting up Field II manually for modeling each cell can be a cumbersome procedure for complicated geometries. A significant simplification is possible under the assumption that the cell deflections are of minor influence to the superposition and that each cell

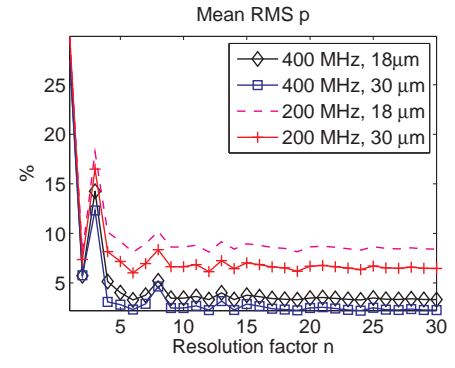

Fig. 3. The mean RMS of the pressure pulses for 20 random points, each solved 1000 times. The error is calculated relatively to a high resolution solution at $10^{4} \mathrm{GHz}$ and $n=30$.

can be considered as a plane piston. Further, this is valid for the assumption that the only physical difference between a full transducer element with each cell modeled (ECM) and a single square model (SSM), where no cells are considered, is the active area. The active area for a SSM is bigger than the one for an ECM. If it is further assumed that the cells are distributed with a pitch equal twice the cell radius, i.e., the boundary rims being in contact, the fraction between the active areas will be

$$
f=\frac{A_{\text {square }}}{A_{\text {cell }}}=\frac{2 r_{c} 2 r_{c}}{\pi r_{c}^{2}}=\frac{4}{\pi},
$$

where $A_{\text {square }}$ is the active area of the SSM, and $A_{\text {cell }}$ is the active area of an ECM. For cell-to-cell pitches larger than the cell diameter the areas to be calculated and the fraction becomes $\frac{A_{\text {square }}}{A_{\text {cell }}}$. A good approximation of the SIR for an ECM can be made with a SSM if the SIR is scaled with the area fraction.

A few pitfalls in relation to this method have to be addressed. First, the start and the end times of the two different SIRs will be different, depending on the location of an observing point relative to the transducer. This has a significant influence if the exact time of flight is required. Second, the exact same energy of the SIR pulses is rarely achieved, i.e. this can only be an approximation. Third, near-field simulations are indeed invalid when using such an approximation.

\section{Simulation}

A program that defines CMUTs in Field II terminology was created. The program sets a user-defined number of circular cells in either a linear one-dimensional or two-dimensional grid to form a square-shaped transducer element. An arbitrary number of elements can be defined to form a transducer array. The plate deflection is set equal the solution of a static deflection model [13]. The cells can be placed with a minimum pitch corresponding to the diameter of the cells. All cells in a particular element are assumed to experience a uniform excitation. The number of MEs required to resolve a single cell is controlled with a resolution factor, $n$. This factor is an integer number and corresponds to the number of MEs that fit across a cell's radius.

To study the error in approximating the ECM with the SSM, a single cell with a radius $r_{c}=18 \mu \mathrm{m}$ and the simulation 


\begin{tabular}{lccr} 
& Points & Solver & Deviation \\
\hline Area deviation & $\{0,0,4.7\} \mathrm{mm}$ & Lines & $0.02 \%$ \\
Pressure deviation & $\{0,0,4.7\} \mathrm{mm}$ & Lines & $0.032 \%$ \\
Pulse-echo deviation & $\{0,0,4.7\} \mathrm{mm}$ & Lines & $0.064 \%$ \\
Mean area deviation & 20 points & Lines & $0.021 \%$ \\
Mean pressure deviation & 20 points & Lines & $0.05 \%$ \\
Mean pulse-echo deviation & 20 points & Lines & $0.10 \%$ \\
Mean area deviation & 20 points & Rect & $0.022 \%$ \\
Mean pressure deviation & 20 points & Rect & $0.051 \%$ \\
Mean pulse-echo deviation & 20 points & Rect & $0.103 \%$ \\
\hline
\end{tabular}

TABLE I

DEVIATION OF THE AREA OF SIRS, PRESSURE PULSES, AND PESIRS BETWEEN A FLAT CELL AND A SCALED VERSION OF THE RESPONSE FROM A SQUARE TRANSDUCER ELEMENT. TWO DIFFERENT FIELD II SOLVERS WERE APPLIED.

\begin{tabular}{lcl}
\hline$V_{\text {bias }}$ & 36 & $\mathrm{~V}$ \\
Young's module & 169 & $\mathrm{GPa}$ \\
Poison ratio $\nu$ & 0.29 & {[]} \\
Gap height $g_{0}$ & 150 & $\mathrm{~nm}$ \\
Plate thickness $t$ & 1.125 & $\mu \mathrm{m}$ \\
$c_{v}$ & 0.43 & \\
$r_{\text {cell }}$ & 18 & $\mu \mathrm{m}$ \\
Exterior pressure & 101.3 & $\mathrm{kPa}$ \\
\hline
\end{tabular}

TABLE III

SIMULATION PARAMETERS USED FOR CALCULATING THE CELL DEFLECTION.

parameters given in Table III is considered. The SIR, the pressure, and the PESIR are calculated with a flat square model of size $2 r_{c}$ times $2 r_{c}$, a circular model without any plate deflection, and a circular model with calculated plate deflection.

A single square transducer element with the size of $5 \times 150$ cells in the lateral and the elevation plane is modeled as well. Each cell has a radius of $r_{c e l l}=18 \mu \mathrm{m}$, and the cell-to-cell pitch is cell $_{p}=38 \mu \mathrm{m}$. A corresponding rectangular element is assumed to have the dimensions $5 \cdot$ cell $_{p} \times 150 \cdot$ cell $_{p}$.

\section{RESUlts}

SIRs calculated at a point $\left\{x_{p}, y_{p}, z_{p}\right\}=\{0,0,4.7\} \mathrm{mm}$ relative to a single flat cell and a corresponding flat rectangular cell with the height and the width of twice the cell radius are shown in Fig. 2. The simulations are conducted at a sampling frequency (SF) of $10^{4} \mathrm{GHz}$ and with the bounding line solver of Field II. In Fig. 2 cell, square, and scaled are the responses from the circular cell, the square element, and the square element scaled with $f$, respectively.

As seen in Fig. 2, the response from a square element is, as expected, spread along a longer time interval. If the pulses $h_{\text {cell }}$ and $h_{\text {scaled }}$ are integrated and the difference in percentage relative to $h_{\text {cell }}$ is found, then the error amounts to $0.02 \%$.

Table I lists the area error for the situation depicted in Fig. 2, together with a RMS comparison between the scaled and the cell SIRs convolved with a $10 \mathrm{MHz}$ pulse and relative to the RMS of the cell model. The RMS of the PESIR pulses are shown as well. The same study with 20 randomly distributed

\begin{tabular}{lccr} 
& Points & Solver & Deviation \\
\hline Mean area deviation & 20 points & Lines & $1.85 \%$ \\
Mean pressure deviation & 20 points & Lines & $5.62 \%$ \\
Mean pulse-echo deviation & 20 points & Lines & $11.12 \%$ \\
Mean area deviation & 20 points & Rect & $1.87 \%$ \\
Mean pressure deviation & 20 points & Rect & $3.99 \%$ \\
Mean pulse-echo deviation & 20 points & Rect & $7.92 \%$ \\
\hline
\end{tabular}

TABLE II

DEVIATION OF THE AREA OF SIRS, PRESSURE PULSES, AND PULSE-ECHO PULSES BETWEEN A DEFLECTING CIRCULAR CELL AND A SCALED VERSION OF THE RESPONSE FROM A SQUARE TRANSDUCER ELEMENT.

points within a space of $10 \cdot r_{\text {cell }} \times 10 \cdot r_{\text {cell }} \times 0.01 \mathrm{~m}$ in front of the cell is shown as the mean of the deviations. Results of using the rectangular "Rect" solver or the bounding line solver "Lines" of Field II is shown.

The same study as for Table I but with the "cell" model deflecting $(33.4 \mathrm{~nm})$ is shown in Table II. Notice that the deviations are significantly different for the two solvers, "Lines" and "Rect". The higher deviations compared to the flat cell simulation are because of the cells' focus point which in this simulation with high resolution influences the phase summation.

The above cells were resolved with a high number of MEs and SF, to ensure exactness of the results. In realistic Field II simulations a SF around $200-400 \mathrm{MHz}$ would have been chosen, which is because of Field II's energy preservation of the pulses. The lowest possible number of MEs is preferred.

Figure 3 shows the mean RMS deviation of the pressure calculated for 20 random points as a function of $n, \mathrm{SF}$, and cell radius. The rectangular solver of Field II was used. The figure reveals that the responses have stabilized after $n=5$, and that the slope of the errors are constant for larger numbers of $n$. Further, it can be identified that the $200 \mathrm{MHz}$ SF yields a relatively large deviation compared to the $400 \mathrm{MHz}$ SF. The latter indicates the importance in considering the relation between ME size and SF, but also the fact that the number of MEs does not have to be large.

The mean times for solving the SIR and the pressure of the 20 random points, each solved 1000 times, can be found in Figs. 4 and 5. From these figures it can be identified, that the solving time is exponentially increasing, but the difference in solving time between $200 \mathrm{MHz}$ and $400 \mathrm{MHz}$ is not significant at low $n$.

\section{A. Simulating a populated transducer element}

Ultrasound imaging simulation requires at least one transducer element fully populated with cells. Consider a single transducer element populated with $5 \times 150$ cells. It was previously shown that the response from the rectangular element can be scaled with (1). It is therefore assumed that within certain limitations this will be applicable for an entire element, where the cell-to-cell spacing prevents the cell boundaries from touching each other, as well. The scaling factor used is 


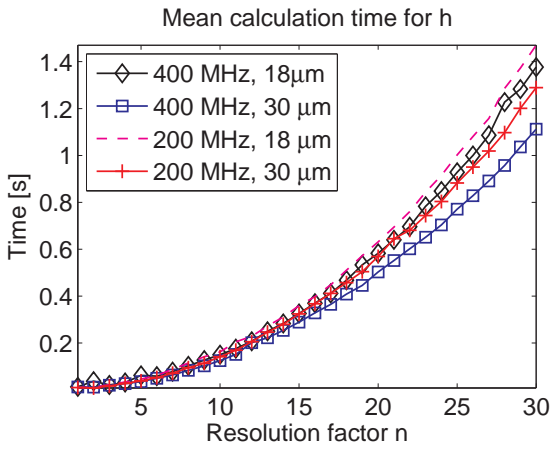

Fig. 4. Mean calculation time of the SIRs of 20 random points. Each point is solved 1000 times.

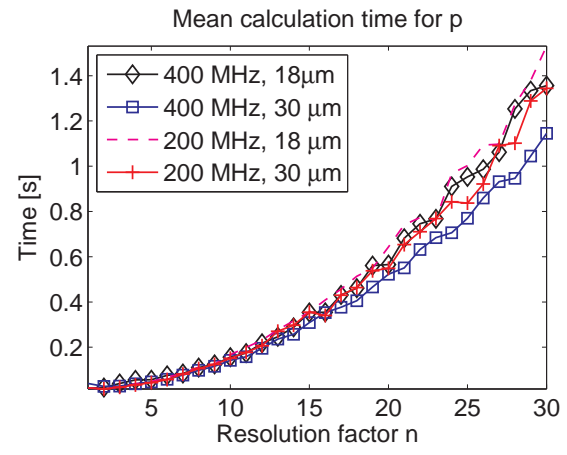

Fig. 5. Mean calculation time for pressure pulses of 20 random points. Each point is solved 1000 times.
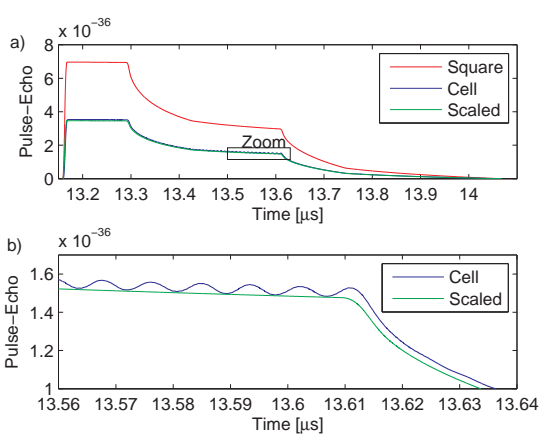

Fig. 6. PESIR of a single point calculated with the rectangular transducer, Square, $5 \times 150$ CMUT cells, Cell, and a scaling of the

"Square" response, Scale a) full pulse shapes.

b) zoom onto (a).

\begin{tabular}{|c|c|c|c|c|c|}
\hline & Points & Solver & Sampling & Deviation & \\
\hline Mean area deviation & 200 points & Rect & $5 \mathrm{GHz}$ & $1.78 \%$ & \\
\hline Mean pulse-echo deviation & 200 points & Rect & $5 \mathrm{GHz}$ & $3.19 \%$ & visible influence on images for high frequency excitation and \\
\hline Mean area deviation & 200 points & Rect & $400 \mathrm{MHz}$ & $3.89 \%$ & od care has to be taken on convergence of the solution \\
\hline Mean pulse-echo deviation & 200 points & Rect & $400 \mathrm{MHz}$ & $5.29 \%$ & ear-field if the cell resnonses are anproximated \\
\hline Mean area deviation & 200 points & Rect & $200 \mathrm{MHz}$ & $4.07 \%$ & lear-held if the cell responses are approximated. \\
\hline Mean pulse-echo deviation & 200 points & Rect & $200 \mathrm{MHz}$ & $4.83 \%$ & REFERENCE \\
\hline
\end{tabular}

TABLE IV

TABLE SHOWING THE DEVIATIONS CALCULATED FOR 200 RANDOM POINTS WITH AN ELEMENT POPULATED WITH 5X150 CELLS

given by the fraction between active areas, which is different from (1) because of cell $_{p}>2 r_{c}$.

A configuration of Field II to model a single element with and without cells was set up. 200 random points were used to calculate the SIR and the PESIR. Integrations of the SIRs were performed and a RMS deviation between PESIRs were calculated. The cell resolution was set to $n=6$, which is based on the results in Fig. 3, and a SFs of $5 \mathrm{GHz}, 400 \mathrm{MHz}$, and $200 \mathrm{MHz}$ were investigated. The results are presented in Table IV.

Table IV reveals that a deviation ranging from $1.7 \%$ to $5.29 \%$ can be found between the two modeling principles. It also reveals that an increase in deviation from lowering the $\mathrm{SF}$ from $5 \mathrm{GHz}$ to $400 \mathrm{MHz}$ is relatively small.

Fig. 6 shows the response from a single point and it further reveals the difference between the models. Figure 6a shows the pulse shapes of the three calculation methods, and Fig. $6 \mathrm{~b}$ shows a zoomed-in version of (a). The ripple response found is a result of the superposition.

\section{Conclusion}

Modeling CMUT cells with Field II is feasible if it is assumed that the CMUT plate moves uniformly and perpendicular to its initial deflection. Circular-shaped cells with spherical deflection can be approximated with flat square elements when each SIR convolution is scaled with the ratio between active areas. An array transducer populated with many cells can be well approximated with a square element, neglecting the cells.
[1] J. A. Jensen, "Field: A program for simulating ultrasound systems," Med. Biol. Eng. Comp., vol. 10th Nordic-Baltic Conference on Biomedical Imaging, Vol. 4, Supplement 1, Part 1, pp. 351-353, 1996b.

[2] J. A. Jensen and N. B. Svendsen:"Calculation of pressure fields from arbitrarily shaped apodized, and excited ultrasound transducers," IEEE Trans. Ultrason., Ferroelec., Freq. Contr., 39, pp. 262-267, 1992.

[3] G. E. Tupholme, "Generation of acoustic pulses by baffled plane pistons," Mathematika, vol. 16, pp. 209-224, 1969.

[4] P. R. Stepanishen, "Transient radiation from pistons in an infinite planar baffle," J. Acoust. Soc. Am., vol. 49, pp. 1629-1638, 1971.

[5] M.I. Haller and B. T. Khuri-Yakub, "A surface micromachined electrostatic ultrasonic air transducer," Proc. IEEE Ultrason. Symp., pp. 12411244, 1994.

[6] Y. Huang, X. Zhuang, E. O. Hæggström, A. S. Ergun, C.-H. Cheng, and B. T. Khuri-Yakub, "Capacitive micromachined ultrasonic transducers with piston-shaped membranes: Fabrication and experimental characterization," IEEE Trans. Ultrason., Ferroelec., Freq. Contr., vol. 56-1, pp. 136-145, 2009.

[7] M. Kupnik, I.O. Wygant, and B. T. Khuri-Yakub, "Finite element analysis of stress stiffening effects in CMUTs," Proc. IEEE Ultrason. Symp., pp. 487-490, 2008.

[8] B. Bayram, E. Hæggström, G. G. Yaralioglu, and B. T. Khuri-Yakub, "A new regime for operating capacitive micromachined ultrasonic transducers," IEEE Trans. Ultrason., Ferroelec., Freq. Contr., vol. 50-9, pp. $1184-1190,2003$.

[9] J. A. Jensen, "A model for the propagation and scattering of ultrasound in tissue," J. Acoust. Soc. Am., vol. 89, pp. 182-191, 1991a.

[10] H. T. O'Neil, "Theory of focusing radiators," J. Acoust. Soc. Am., vol. 21-5, pp. 516-526, 1949.

[11] A. Penttinen and M. Luukkala, "The impulse response and nearfield of a curved ultrasonic radiator," J. Phys. D: Appl. Phys., vol. 9, pp. $1547-1557,1976$.

[12] M. Arditi, F. S. Forster, and J. Hunt, "Transient fields of concave annular arrays," Ultrason. Imaging, vol. 3, pp. 37-61, 1981.

[13] I. O. Wygant, Three-dimensional ultrasound imaging using custom integrated electronics combined with capacitive micro machined ultrasonic transducers. Phd Thesis at the Department of Electrical Engineering, Stanford University, California, 2008. 